\title{
Pistrak e a escola politécnica: contribuições à Educação
}

\author{
Ambiental \\ Pistrak y la escuela politécnica: contribuciones a la Educación Ambiental \\ Pistrak and the polytechnic school: contributions to Environmental \\ Education
}

\author{
Daniele Barros Jardim ${ }^{1}$ \\ Andressa Queiroz Souza ${ }^{2}$ \\ Danielle Müller de Andrade ${ }^{3}$
}

\begin{abstract}
Resumo
O presente trabalho busca refletir sobre os princípios da construção de uma escola politécnica e suas aproximações com a Educação Ambiental no Ensino Formal, trazendo contribuições do pensamento do pedagogo russo Moisey Pistrak para o enfrentamento dos problemas educacionais atuais. Tal pensamento visava o desenvolvimento de uma ação educativa que, ao considerar a relação entre trabalho, conhecimento e educação sinalizava para uma educação que respondia às demandas produtivas e sociais daquele período. Desta forma, buscamos apontar alguns elementos desta proposta de escola a fim de trazê-las para o campo da Educação Ambiental desenvolvida no âmbito do ensino formal, considerando-as enquanto propostas pedagógicas de cunho transformador da realidade.
\end{abstract}

Palavras-Chave: Escola Politécnica; Educação Ambiental; Ensino Formal.

\section{Resumen}

El presente trabajo busca reflexionar sobre los principios de la construcción de una escuela politécnica y sus aproximaciones con la Educación Ambiental en la Enseñanza Formal, trayendo aportes del pensamiento del pedagogo ruso Moisey Pistrak para el enfrentamiento de los problemas educativos actuales. Tal pensamiento pretendía el desarrollo de una acción educativa que, al considerar la relación entre trabajo, conocimiento y educación, señalaba para una educación que respondía a las demandas productivas y sociales de aquel período. De esta forma, buscamos apuntar algunos elementos de esta propuesta de escuela a fin de traerlas al campo de la Educación Ambiental desarrollada en el ámbito de la enseñanza formal, considerándolas como propuestas pedagógicas de cuño transformador de la realidad.

Palabras claves: Escuela Politécnica; Educación Ambiental; Enseñanza Formal.

\begin{abstract}
The present work seeks to reflect on the principles of the construction of a polytechnic school and its approaches with Environmental Education in Formal Education, bringing contributions of the thinking of the Russian pedagogue Moisey Pistrak to the confrontation of the current educational problems. Such thinking was aimed at developing an educational action that, when considering the relationship between work, knowledge and

\footnotetext{
${ }^{1}$ Doutoranda e Mestra em Educação Ambiental; Universidade Federal do Rio Grande -FURG; Rio Grande, Rio Grande do Sul, Brasil; danielejardim@furg.br

${ }^{2}$ Mestre em Educação Ambiental, Universidade Federal do Rio Grande, Rio Grande- FURG, Rio Grande do Sul. E-mail: queirozz.andressa@gmail.com

${ }^{3}$ Doutora em Educação Ambiental, Universidade Federal do Rio Grande, Rio Grande - FURG, Rio Grande do Sul. E-mail:, danielleca@gmail.com
} 
education, signaled for an education that responded to the productive and social demands of that period. In this way, we seek to point out some elements of this school proposal in order to bring them to the field of Environmental Education developed within the scope of formal education, considering them as pedagogical proposals that transform reality.

Keywords: Polytechnic School; Environmental Education; Formal Teaching.

\section{Introdução}

Este ensaio tem por objetivo refletir sobre os princípios da escola politécnica enquanto lugar para o desenvolvimento de uma Educação Ambiental comprometida com a transformação social, no ensino formal. Assim temos como ponto de partida a terceira obra de Moisey Pistrak (2015) "Ensaios sobre a escola politécnica", organizada durante fortes debates teóricos realizados em 1917 durante a revolução russa, buscando a partir dos conceitos nela desenvolvidos como a incorporação do trabalho de natureza politécnica, relacioná-la com o contexto atual, mais especificamente com a Educação Ambiental. A contribuição desta obra está no avanço sobre o debate entre ensino e trabalho, na perspectiva de compreensão da centralidade da categoria trabalho nas discussões que propõem a superação das relações sociais capitalistas.

Moisey Mikhailovich Pistrak (1988-1937) foi um dos principais pensadores ativos da Revolução Russa em 1917 e participou da construção da escola soviética e do desenvolvimento da pedagogia marxista na União das Repúblicas Socialistas Soviéticas, isto é, um espaço onde houvesse associação e teorização de práticas educativas protagonizadas pelos trabalhadores visando à construção de novas relações sociais de caráter socialista. Era professor e militante socialista contemporâneo dos pensadores Nadyezhda Krupskaya (19171929), Anton Makarenco (1888-1939), Anatoli Lunatcharsky (1875-1933), Viktor Shulgin (1894-1965) e Vasyl Sukhomlinski (1918-1970) e acreditava que a educação social, baseada no materialismo dialético como forma de produção de conhecimento, era um dos caminhos necessários para a formação de pessoas ativas, participativas, solidárias, comprometidas a mudança e com a transformação social.

Compreender os princípios científicos e tecnológicos da escola politécnica, a partir de Pistrak, relacionando-os com os processos produtivos e demandas atuais, configura-se como uma possibilidade de alavancar propostas de Educação Ambiental no ensino formal, com vistas à formação de indivíduos participantes, críticos e comprometidos com o movimento de transformação social.

Para tanto o texto está organizado da seguinte forma: em um primeiro momento apresentamos uma síntese sobre a obra "Ensaios sobre a escola politécnica" no esforço de 
compreender alguns princípios da escola politécnica. Já no segundo momento buscamos apontar algumas aproximações dos princípios da escola politécnica com as proposições da Educação Ambiental no âmbito do ensino formal, ou seja, apontaremos as convergências destas duas propostas pedagógicas, tecemos nossas considerações até o momento, as quais entendemos comprometidas com a formação humana e a transformação social.

\section{Apontamentos sobre a obra "Ensaios sobre a Escola Politécnica"}

A obra "Ensaios sobre a escola politécnica" traz a reflexão de Pistrak sobre a proposta de efetivação da educação politécnica, na Rússia, durante o período de transição, o qual envolveu a década de 20, mais especificamente o período entre os anos 1923 e 1929. É fruto das teses elaboradas pelo autor, oriundas de palestras sobre a escola politécnica no sentido da construção de uma sociedade socialista.

A educação politécnica, segundo Pistrak (2015), associada a uma educação social, busca articular a relação entre o ensino, o trabalho e o conhecimento. Destaca que não se tem um conceito de politecnismo preciso e não pretende realizar tal definição, mas, normalmente, as definições do termo apoiam-se prioritariamente em Marx (1818-1883) e Engels (18201895), bem como em Lenin (1870-1924), entre outros pensadores contemporâneos já supracitados.

Dentre as principais características da escola politécnica nos são trazidas as bases pelas quais a pedagogia socialista está embasada para traçar os caminhos para a educação, que tem como eixo não só a incorporação da dimensão do trabalho na escola, mas a incorporação do trabalho de natureza politécnica. Assim, não isoladamente construída, tal pedagogia situa-se a partir das ideias do Partido Comunista da União Soviética e do documento do I Congresso da Primeira Internacional. O documento traz características de escola politécnica, no qual o autor apresenta como ponto de partida o Programa do Partido VKP (Partido Comunista da União Soviética), e aponta que a educação deve ser gratuita e obrigatória a crianças e jovens, de ambos os sexos, com idades entre seis e dezessete anos.

Essa ideia de educação tem por objetivo conhecer a partir da praticabilidade da teoria e a teorização da prática todos os ramos da produção, ou seja, os estudos associados com o trabalho socialmente produtivo fazem da escola politécnica uma possível alavanca para a 
modificação das pessoas, com vistas ao socialismo. Contudo, não devemos considerar essa característica como básica da escola politécnica.

O Programa do Partido tem como base a Resolução da Primeira Internacional, onde a educação é vista a partir de três categorias: a intelectual, a física e a politécnica. Dentre estas Pistrak (2015) também aponta como características necessárias a educação politécnica, a participação direta das crianças no trabalho produtivo; o conhecimento teórico e prático dos princípios científicos do trabalho produtivo e a união do trabalho produtivo com a educação física e o desenvolvimento intelectual, buscando a superação do trabalho socialmente produtivo para o trabalho socialmente necessário. Estas características são traços distintivos da escola politécnica e estão de acordo com o pensamento de Marx quanto à sugestão da união do trabalho físico, do ensino e da ginástica e permitem a compreensão do politecnismo como um novo sistema de educação.

A partir destes princípios Pistrak, pensa nas singularidades que cada escola precisa ter frente ao lugar que ocupam, chamando a atenção para as diferenças encontradas entre campo e cidade. Pistrak (2015) ao se referir a distinção entre cidade e campo o autor compreende que as necessidades e formação do campo são outra as crianças do campo quando ainda pequenas conseguem participar de forma mais ativa neste trabalho com o campo se comparadas às crianças da cidade. Também salienta que as escolas deveriam se adaptar às diferentes culturas e geografias, obedecendo ao princípio da regionalização.

A respeito da adaptação das fábricas às crianças e jovens, Pistrak (2015) aponta para a relação de disputa entre os trabalhadores e estudantes, bem como a questão da exploração, característica importante do capitalismo. Como forma de amenizar ou até mesmo superar esta dificuldade de relação propõe a implantação de oficinas escolares.

Quanto ao Plano Quinquenal, a escola politécnica objetiva preparar trabalhadores qualificados, elevando consequentemente o nível cultural da população adulta e erradicando o analfabetismo. Neste sentido, com o ensino politécnico, reforçado pelo trabalho coletivo, seria possível mudar a natureza do trabalhador, tornando-o mais consciente do quão é importante para o processo de produção.

Pistrak (2015) ao conceituar educação politécnica nos conta que é preciso [...] "conhecer, na teoria e na prática, todos os principais ramos da produção" (2015, p.79), reflete sobre como o conhecimento destes principais ramos da produção podem ser tratados a partir das variadas condições das escolas especificamente com relação à escola do campo, a ampliação das conexões entre escola do campo e a indústria, incluindo assim o ramo da comunicação, transporte e indústria química. A escola politécnica da cidade pode ser 
concebida como uma escola fabril, estando junto às empresas. Para isto seriam divididas em complexos politécnicos (ensino primário) e complexos técnicos (ensino secundário).

Com relação aos conteúdos e métodos do trabalho educativo é preciso a compreensão de que o politecnismo não é somente um complexo tecnológico, mas sim um complexo social, o qual aponta para a necessidade de ruptura com o sistema educacional vigente, daí a dificuldade de sua efetivação. Pistrak (2015) apresenta algumas das dificuldades encontradas quando da implementação da escola politécnica. Entre elas o conflito entre a forma tradicional, disciplinar do material educativo e a dificuldade de constituir um núcleo comum, que agregasse o núcleo principal ou geral (teórico) e o núcleo secundário (prático - baseado na ilustração, aplicação). Esse conflito estaria também relacionado com a manutenção de diretrizes curriculares antigas, com a falta de profissionais capacitados e a falta de incentivo à educação politécnica.

Pistrak (2015) destaca ainda a necessidade da contextualização dos conteúdos e aponta a interdisciplinaridade como um caminho para a efetivação da educação politécnica, compreendendo que a educação politécnica é um caminho para transformação social. O autor entende como objetivo desta educação a formação pessoas capazes de pensar política e tecnicamente, bem como de buscar de forma autônoma novos conhecimentos que julguem necessários.

Com relação às metodologias de ensino Pistrak (2015) salienta que método de complexos não obteve sucesso, pois o eixo politécnico foi fragmentado e que o trabalho socialmente necessário também não se efetivou devido à estrutura do material educativo, o qual não estava adequado às demandas. No mesmo sentido Krupskaya, que era companheira de Lênin, considerou o sistema de complexos como um fetiche e que os professores, para facilitar o seu trabalho, reduziam às exigências do método.

Pistrak (2015) aponta como solução metodológica a criação de uma concepção concreta geral da educação politécnica. Tal concepção é composta por três linhas: habilidades e experiência, que corresponde ao eixo do trabalho politécnico; natureza e volume dos conteúdos, correspondendo ao eixo do ensino; e conhecimentos gerais, os quais são determinados pelo eixo do ensino e permitem a ampliação da visão de mundo. Neste sentido a escola seria dividida em três núcleos ou períodos.

O primeiro é o núcleo propedêutico, dos seis aos doze anos e o segundo o núcleo prático, dos 13 aos 15 anos. Neste núcleo está contemplada a história natural; a alfabetização matemática; a técnica e a tecnologia; a politecnia do trabalho e as ciências sociais e línguas. $\mathrm{O}$ 
terceiro núcleo é o teórico (ideológico), dos quinze aos dezessete anos, onde são realizados trabalhos práticos.

Nesse sentido, os elementos educativos e instrutivos, ou seja, os conteúdos, o autor destaca as ciências sociais; a linguagem e a literatura; a educação física e a educação artística. Para Pistrak (2015) os conteúdos das ciências sociais devem permitir o entendimento de como a técnica se transfigura em economia, a partir da integração dos conhecimentos, possibilitando assim, que os estudantes relacionem política com economia, bem como que compreendam as tarefas imediatas da industrialização no sentido de organizar a produção a partir da elaboração de mecanismos de controle pautado no trabalho coletivo, onde cada integrante possa atuar em todas as funções.

No que diz respeito à linguagem e a literatura, o autor destaca que este campo do conhecimento deva auxiliar os estudantes a expressarem-se de maneira breve, precisa e clara e nesta perspectiva aponta o método de trabalho através de projetos, a partir do encaminhamento do trabalho socialmente necessário, como uma possibilidade de reestruturação do trabalho educativo. A adoção do método de projetos permitiria uma maior organização do processo educativo, diminuindo entraves como a ociosidade, a negligência e a falta justificada.

A Educação Física é outro elemento destacado pelo autor, que na escola politécnica tem por objetivo o desenvolvimento da agilidade, da rapidez, da destreza, da concentração e da coordenação corporal. Estes aspectos conduziriam a um desenvolvimento multilateral do corpo bem como a autocorreção postural. Enquanto a Educação Artística, na escola politécnica, deve estar relacionada com a alfabetização gráfica, questionando assim a arte tradicional, como a pintura, a literatura, a música e o teatro. Pistrak (2015) também aponta para a necessidade de ligar arte e tecnologia.

Diante destas disciplinas o trabalho politécnico, na escola primária é a principal via de introdução do politecnismo e podem ser consideradas determinantes do eixo politécnico, considerando os objetivos, o planejamento, os conteúdos e as abordagens metodológicas do trabalho. Assim o ensino politécnico desenvolve-se a partir de quatro principais formas de trabalho: o dia-a-dia, as oficinas escolares, o trabalho agrícola e o trabalho na fábrica, sendo estes trabalhos classificados de acordo com a idade dos estudantes.

No primeiro nível, ensino primário, desenvolvem-se trabalhos caseiros, que devem ser realizados de forma precisa do início ao fim. Nesta fase, a partir do estímulo ao trabalho coletivo, os estudantes devem ser capazes de ordenar, planejar e executar trabalhos com materiais diversos e simples. Como método de ensino para esta fase, deve ser combinado o 
método de tarefa-alvo, priorizado nesta fase, com atividades ordenadas e de livre escolha com um método operacional, onde os processos são desenvolvidos de forma separada e com o aumento da complexidade.

A sala de trabalho é vista como ponto de partida para o conhecimento da tecnologia dos diferentes materiais. Esta sala deve estar relacionada com o contexto local, bem como dispor de instrumentos adequados à tarefa a ser realizada, bem como aos estudantes. Pistrak (2015) destaca também a necessidade da qualificação dos professores e da reestruturação do sistema de ensino pedagógico e indica como pessoa capaz de desenvolver as atividades desta sala os dirigentes dos complexos, não necessariamente professores.

Para o segundo nível, que contempla o $5^{\circ}, 6^{\circ}$ e $7^{\circ}$ anos, o autor destaca o trabalho nas oficinas, tendo como material básico o metal e a madeira, no qual buscariam desenvolver o aprimoramento e domínio da técnica a fim da realização de um trabalho preciso e limpo. Nas oficinas o método de disciplinas é superado pelo método operacional, considerando as características da fase da adolescência, como a diminuição da criatividade e a necessidade do aumento do gasto energético, que seria favorecido pelo treinamento físico. Nesta fase também é interessante reduzir a carga de trabalho intelectual na escola.

Pistrak faz ainda uma crítica às considerações feitas por Gastev (1882-1939), revolucionário russo e chefe do Instituto Central do Trabalho, colocando-se contrário a algumas de suas teses ao considerar que a educação politécnica está para além da politecnia do trabalho, que o processo de industrialização tem uma ligação estreita com a escola politécnica, que é preciso considerar os aspectos educacionais ou pedagógicos, bem como incluir a agricultura enquanto ramo da produção e que é necessário uma multiplicidade de conhecimentos a fim de evitar-se o monotecnismo.

Em síntese, podemos dizer que o ensino deve relacionar o trabalho com o princípio educativo, a fim de analisar a realidade atual do ponto de vista marxista, no qual busca tornar esse ensino compreensivo e claro, cheio de sentido para o trabalho. A partir dessa premissa é possível refletir que a relação entre homem e natureza é mediada pelo trabalho e ao realizarmos essa compreensão, o trabalho adquire um duplo sentido, pois ao mesmo tempo em que é elemento do ser social; com o surgimento do capitalismo, o trabalho assumiu um caráter alienador.

Assim, depois de estudar, compreender e refletir sobre os princípios da construção de uma escola politécnica, a partir desta obra de Pistrak (2015), buscaremos realizar aproximações com a Educação Ambiental desenvolvida no âmbito do ensino formal, enquanto proposta pedagógica, na próxima sessão. 


\section{Aproximações dos princípios da escola politécnica com a Educação Ambiental enquanto proposta metodológica}

A leitura da obra de Pistrak (2015) nos permite compreender a práxis de uma escola de cunho socialista que a apoiada em práticas que são protagonizadas por trabalhadoras e trabalhadores que pretendem colaborar com a construção de novas relações sociais para além do que estava presente no resto do mundo que tem como modo de produção o capital. A escola politécnica nos oferece outra forma de pensar sobre a escola nos dias atuais. Mediante nossas leituras e fazendo a aproximação dos princípios da escola politécnica com a Educação Ambiental enquanto proposta pedagógica no Ensino Formal, compreendemos que através da educação acontece a transformação do pensamento e uma nova ética da solidariedade, que possui como pano de fundo novos modos de estar com os outros, consigo mesmo e com o planeta.

Uma escola politécnica requer a formação integral dos seres humanos onde não seja desenvolvida e estimulada a realização da técnica pela técnica, ou seja, onde não seja efetivado o pragmatismo na produção, mas sim estimulado e possibilitado um conhecimento sobre o saber fazer. Compreendemos esta formação enquanto práxis, como possibilidade de conhecer a totalidade que envolve o processo produtivo, corroborando com $\mathrm{o}$ desenvolvimento humano. Isto é, a politecnia corrobora para unir o que está separado a fim de conhecer o todo; distinguir as partes sem separá-las, bem como reconhecê-las novamente em suas inter-relações, o que é extremamente necessário para compreender a realidade onde estamos inseridos e que estamos envolvidos.

Na perspectiva da formação integral dos seres humanos, bem como da compreensão da educação, enquanto práxis social, tanto o ensino politécnico quanto a Educação Ambiental, se constituem uma possibilidade de, por meio da ação pedagógica, ou seja, da práxis, promover a transformação social. A práxis, como sugere Freire

[...] é reflexão e ação dos homens sobre o mundo para transformá-lo. Sem ela, é impossível a superação da contradição opressor-oprimidos (...). Por isto, inserção crítica e ação já são a mesma coisa. Por isto, também é que o mero reconhecimento de uma realidade que não leve a esta inserção crítica (ação já) não conduz a nenhuma transformação da realidade objetiva, precisamente porque não é reconhecimento verdadeiro. (FREIRE,2011. p. 52-53) 
A educação, de acordo com Pistrak (2015), deveria centrar-se no trabalho social e pautar-se na formação de pessoas conscientes, não alienadas, que pudessem compreender criticamente o presente para alcançar um futuro mais solidário. Tal consideração se aproxima de alguns pressupostos da Educação Ambiental, no sentido de buscar a tomada de consciência e a emancipação humana, bem como a superação de todas as formas de opressão.

Neste sentido, tanto a escola politécnica, quanto a Educação Ambiental, promoveriam a reflexão acerca da relação entre trabalho, conhecimento, ensino e educação, favorecendo a homens e mulheres a compreensão de seu papel na luta contra o capitalismo, bem como o papel do trabalhador e trabalhadora no contexto em que estão inseridos, a partir da aprendizagem de conhecimentos tanto das ciências naturais, quanto das sociais. Conforme destaca Pistrak "O trabalho na escola, enquanto base da educação deve estar ligada ao trabalho social, à produção real, a uma atividade concreta socialmente útil” (PISTRAK, 2011, p. 30).

A integração dessa relação estabelecida por Pistrak nos faz pensar que é necessário um apelo ao "espírito interdisciplinar" (JAPIASSU, 2006), pois ele só acontece através de trocas a fim de formar novos saberes, o que é um dos princípios que a politecnia sugere. Estes novos saberes devem refletir sobre a realidade complexa exigindo um olhar globalizante para a superação dos problemas socioambientais. Desse modo, a interdisciplinaridade almejada pela integração surge para além de unir pontos em comum, mas sim para inter-relacionar saberes emergentes no âmbito escolar.

A interdisciplinaridade, compreendida como um processo de integração de disciplinas e campos do conhecimento tem como premissa o diálogo e o compartilhamento do processo educativo. As práticas interdisciplinares valorizam os saberes e possibilitam a reflexão crítica sobre os processos de ensino-aprendizagem. Tal como sugere Loureiro (2006)

[...] é uma prática intersubjetiva que associa conhecimentos científicos e não científicos e relaciona o relacional com o intuitivo, o cognitivo com o sensorial, buscando a construção de objetos de conhecimento que se abram para novas concepções e compreensões de mundo (natural, estrito senso e histórico) e para a constituição do sujeito integral. (LOUREIRO, 2006, p. 76)

Nestes termos, a Política Nacional de Educação Ambiental (PNEA - Lei ${ }^{\circ}$ 9.795/1999) no art. $1^{\circ}$ entende por Educação Ambiental os processos por meio dos quais o indivíduo e a coletividade constroem valores sociais, conhecimentos, habilidades, atitudes e competências voltadas para a conservação do meio ambiente. Sendo no art. $2^{\circ}$ considerada como um componente essencial e permanente da educação nacional, devendo estar presente, 
de forma articulada, em todos os níveis e modalidades do processo educativo, em caráter formal e não-formal, o que também demonstra as aproximações com os princípios da escola politécnica.

Segundo Vasconcellos (2002) a presença, em todas as práticas educativas, da reflexão sobre as relações dos seres entre si, do ser humano com ele mesmo e do ser humano com seus semelhantes é condição imprescindível para que a Educação Ambiental ocorra. Dentro desse contexto, sobressaem-se as escolas politécnicas, como espaços privilegiados na implementação de atividades que propiciem essa reflexão, já que permitem aos estudantes relacionar o trabalho produtivo com as demandas sociais e ambientais.

Desta forma, percebemos tanto a inserção da dimensão política na educação, quanto no trabalho pedagógico. E, sendo um ato político, a educação ambiental ou politécnica, prescinde de posicionamento, ou seja, não é nem pode ser neutra. Tal como sugere Freire (1996) ao destacar que a educação, como forma de intervenção no mundo é política, diretiva e alicerçada na educabilidade do ser humano, o qual deve ser compreendido enquanto ser histórico, inacabado e com possibilidade de tornar-se consciente, ou seja, com a possibilidade de vir a ser.

A realidade presente em certos currículos nos âmbitos formais do ensino que compõem a formação de sujeitos, uma formação que se distancia do real, de maneira a fragmentar o conhecimento e assim proporcionar a estes uma compreensão distorcida do real, mutila a capacidade do ser humano e nega violentamente a sua ontologia a de "ser mais humano". Daí a importância da contextualização bem como da adoção de metodologias de ensino pautadas na participação e no diálogo para que se possa efetivar uma educação para a transformação social, conforme Pistrak (2011) sobre os métodos de ensino.

O objetivo que os alunos devem atingir é não somente estudar a realidade atual, mas também se deixar impregnar por ela. A consequência é que os antigos métodos de ensino não podem mais servir: é preciso estudar os fenômenos em suas relações, sua ação, e dinâmica recíprocas, é preciso demonstrar que os fenômenos que estão acontecendo na realidade atual são simplesmente parte de um processo inerente ao desenvolvimento histórico geral, [...] (PISTRAK, 2011, p. 27)

Desta forma, a presença de uma Educação Ambiental crítica em um currículo se estabelece na compreensão de que nenhum conhecimento a ser organizado na escola pode estar fora da vida cotidiana, nenhum currículo que se proponha crítico pode buscar formar sujeitos, sem considerar a sua história. Na tentativa de compreendermos o mundo na 
criticidade precisa, se faz necessário uma visão de mundo em que nos colocamos como sujeitos de nosso quefazer e não meros espectadores deste.

Para as aproximações que pretendemos realizar entre os princípios da escola politécnica e a Educação Ambiental, se faz necessária a compreensão do movimento na qual está se constituindo o mundo, bem como os modos de produção no qual produzimos a nossa existência. A própria história nos mostrou como se deram as transformações dos modos de produção, movidos pela luta de classes, o mundo do trabalho foi se transformando (TONET, 2013).

A proposta pedagógica de Pistrak, direcionada ao ensino primário e secundário, buscava romper com a educação tradicional e para isto questionava tanto os conteúdos desenvolvidos, quanto às metodologias de ensino. Para o pedagogo russo, os conteúdos e métodos de ensino deveriam "[...] ajudar os alunos a se apropriarem solidamente dos métodos científicos fundamentais para analisar as manifestações da vida. A se apropriarem dos conhecimentos indispensáveis para conquistar a vida moderna!” (PISTRAK, 2011, p.97).

De certa forma, buscando aproximá-lo com autores da contemporaneidade, podemos relacioná-lo com Paulo Freire (1921-1997), que se contrapôs a educação tradicional, denominada por ele de educação bancária, propondo outra educação libertadora e transformadora. A pedagogia de Paulo Freire traz elementos essenciais para pensarmos num processo educativo que relaciona à valorização da diversidade cultural e o respeito ao outro por meio do diálogo, da conscientização e da politização dos educandos, no sentido de identificá-los como sujeitos históricos e críticos da sociedade. Freire vê na educação uma forma política de transformar a sociedade, para que esta se torne mais justa e igualitária.

Portanto, Pistrak durante o período de transição da Revolução Russa ao socialismo, assim como Freire no Brasil, propõe repensar a lógica de organização da escola básica, onde haja o vínculo entre trabalho e estudo, e que este seja a chave metodológica para colocar em prática a concepção de conhecimento do materialismo histórico dialético, isto é, um método de compreensão e análise dos fenômenos a partir da realidade. Para tanto, como alternativa aos inúmeros problemas educacionais desencadeados durante a Revolução Russa, surge a proposta de construir uma escola politécnica.

A partir de uma compreensão de mundo crítica é necessário compreender a realidade em sua totalidade, na tentativa de investigar as contradições nela presentes, os movimentos que subsidiam a nossa existência. Portanto, é imprescindível desvelar as mazelas que sustentam o capitalismo este que produz as desigualdades presenciadas em nosso cotidiano. 


\section{Considerações até o momento}

A educação é um processo de aprendizagem que propicia ao sujeito que o mesmo crie uma visão crítica da realidade, bem como uma atuação consciente no seu ambiente social e natural. Logo, uma proposta pedagógica de Educação Ambiental no ensino formal precisa considerar o processo de ensino-aprendizagem num contexto mais amplo, vinculando a educação a uma realidade social, econômica, política e cultural. Uma proposta pedagógica de Educação Ambiental tem que considerar que os grupos sociais se apropriam de maneiras diferentes dos recursos naturais, em função de diversos fatores como históricos, econômicos e culturais.

Nesse contexto, a pedagogia marxista de Pistrak, bem como a pedagogia de Freire traz elementos essenciais para pensarmos nesse processo educativo, principalmente com relação à valorização da diversidade cultural, do respeito ao outro e tudo isso se dá por meio do diálogo, da conscientização e da politização dos educandos, no sentido de identificá-los como sujeitos históricos e críticos da sociedade.

No Brasil, uma aproximação da educação com o trabalho é feita a partir de uma perspectiva diferente da proposição de Pistrak. O artigo 39 da Lei de Diretrizes e Bases da Educação Nacional (LDB, 9394/96) trata da educação profissional e tecnológica, a qual deve ser desenvolvida nos níveis básico, técnico e tecnológico para atender aos diferentes setores da economia, ou seja, formar mão de obra qualificada para atender as demandas do mercado. Contudo, a educação profissional brasileira não apresenta os princípios da escola politécnica proposta por Pistrak, já que nela o trabalho não é o princípio educativo, fundamento da escola politécnica, fonte de conhecimento e de formação para a vida, mas sim o fim do processo educativo, a meta a ser atingida. Assim, a educação profissional brasileira nos parece distanciar-se de uma formação humana que vislumbre a superação das formas de opressão, bem como que promova o fortalecimento de uma sociedade socialista.

Entendemos que os principais princípios da construção de uma escola politécnica apresentados, como refletir sobre a relação escola-trabalho, desenvolvidos por Pistrak, são práticas que expressam a Educação Ambiental como proposta pedagógica no ensino formal e que não é a mesma desenvolvida pelo ensino profissional e tecnológico do Brasil. A Educação Ambiental também tem por função estabelecer uma postura crítica frente às questões socioambientais, mas para tanto é preciso um conhecimento sobre as condições históricas da sociedade em que se vive, o que a politecnia também preconiza. 
Dessa forma, pensamos que a Educação Ambiental pode se transformar em uma prática transformadora e politicamente ativa, capaz de construir uma sociedade mais autônoma e justa, compreendendo o mundo e agindo nele de forma crítica e a escola politécnica, que traz o trabalho como princípio educativo, pode ser a matéria-prima da crítica social das relações de trabalho existentes. Ao compreendermos Educação Ambiental como educação política e ao vivenciar no ambiente escolar a relação escola-trabalho estamos alcançando, na práxis, a análise destas relações entre homem e natureza, homem e trabalho, bem como definindo processos de aprendizagem de transformação social.

Portanto, consideramos que estas práticas e princípios da Escola Politécnica expressam mais precisamente uma Educação Ambiental Crítica, pois estão comprometidas com um projeto de educação que propõe uma transformação social integral, trazendo em seu cerne valores humanistas e socialistas, que ao transformar a ação humana, transforma o mundo. Essa educação pode-se chamar de crítica, pois realiza a mediação entre a construção social de conhecimentos à vida dos sujeitos, que são autores da sua própria história.

\section{Referências}

BRASIL. Lei n 9.795, de 27 de abril de 1999. Dispõe sobre a Educação Ambiental, Institui a Política Nacional de Educação Ambiental e dá outras providências.

BRASIL. Lei no 9.394, de 20 de dezembro de 1996. Estabelece as Diretrizes e bases da educação nacional.

FREIRE, P. Pedagogia da Autonomia. São Paulo: Paz e Terra, 1996.

FREIRE, P. Pedagogia do Oprimido. 50 ed. Rio de Janeiro: Paz e Terra, 2011.

JAPIASSU, H. O espírito interdisciplinar. In: Cadernos EBAPE.BR. vol.IV. n 3, outubro de 2006. p.1-8 (Periódico da EBAPE/ texto em PDF).

LOUREIRO, C. F. B. Trajetória e fundamentos da educação ambiental. 2. ed. São Paulo: Cortez, 2006.

PISTRAK, M M. Ensaio sobre a escola politécnica. 1ed. São Paulo: Expressão Popular, 2015. $256 \mathrm{p}$.

PISTRAK, M. M. Fundamentos da escola do trabalho. 3ed. 1ed. São Paulo: Expressão Popular, 2011. 192p. 
VASCONCELLOS, H. S. R. A pesquisa-ação em projetos de Educação Ambiental. In: PEDRINI, A. G. (org). Educação Ambiental: reflexões e práticas contemporâneas. 5 ed. Petrópolis: Vozes, 2002, p. 260-289.

TONET, I. Método Científico. Uma abordagem Ontológica. 1 ed. São Paulo: Instituto Luckás, 2013. 